\title{
PHYTOBUFFERING OF LOWER CHLORINATED BENZENES THROUGH WILLOWS AT THE PPI SUPERFUND SITE
}

\author{
${ }^{1}$ P. B. Jones Jr., ${ }^{2}$ R. R. Kommalapati, and ${ }^{1}$ W. D. Constant \\ ${ }^{\prime}$ Department of Civil and Environmental Engineering, Louisiana State University, Baton \\ Rouge, LA 70803; Phone: (225) 578 6770; Fax: (225) 578 5043; ${ }^{2}$ Department of Civil \\ Engineering, PO Box 4249, Prairie View A\&M University, Prairie View, TX 77446; Phone: \\ (936) 857 2418; Fax: (936) 8574125.
}

\begin{abstract}
A series of phytobuffering bench-scale experiments using an extraction bed followed by a plant "bioreactor" was performed using streambed sediment from a nearby Superfund site. Experiments consisted of investigating the fate and transport of a mixture of lower chlorinated benzenes (monochlorobenzene, (MCB), 1,2 and 1,3dichlorobenzene (DCB), and 1,2,4-trichlorobenzene (TCB)) at 10-20 ppm sediment loading. These compounds are representative of the degradation products of HCB (hexachlorobenzene) in the Baton Rouge Bayou and Devil's Swamp area at the Petro Processors Inc. Superfund site. Fast, slow, and cyclic flow rates were used as representative conditions found during rain events in the area. Willow cuttings obtained from the site were developed into small plants to measure uptake in the dynamic system. The rates of plant capture of contaminants from contaminated sediment were experimentally estimated under various flow conditions and a mathematical model for the plant uptake rate of the plant "reactor" system was developed. Estimation of the buffering effect expected in these bayou-plant systems was determined by scale up of the kinetic data using the model results. Results indicated that for both steady and transient systems, the willow trees provided a significant buffering of the contaminant flux. Rate coefficients were obtained using an unsteady state analytical model and the experimental data. Cyclic flow resulted in the highest rate coefficients followed closely by slow flow, and the fast flow resulted in the lowest of the rate coefficients. Finally, based upon the uptake rates determined, projections were made by scaling up the developed model to 20 years (current site age) and over 100 acres (contaminated area of the swamp). The lower chlorinated benzenes buffered by the willows ranged from 34 tons for slow flow, 52 tons for cyclic flow, and 102 tons for fast flow, with an average of about 63 tons of the contaminants.
\end{abstract}

Key words: phytoremediation, chlorinated benzenes, uptake rates, willow trees, attenuation

\section{INTRODUCTION}

Phytoremediation is the use of vegetation for in situ treatment of metals, organics, and nutrient contaminants. A natural process is carried out by a plant's root system and rhizospheric microorganisms to remove, degrade, transport, or contain contaminants. Plants have shown the ability to survive higher concentrations of hazardous waste than most other organisms. Also, vegetation can substantially influence the local hydraulics of a shallow aquifer, thus controlling the migration of a contaminant plume (Nyer and Gatliff, 1996). The cost of various phytoremediation projects can vary from 10 to 50 percent of that for physical, chemical, and thermal techniques (Rock and Sayle, 1998). Contamination sites are amenable to one of five applications of phytoremediation: phytotransformation, rhizosphere bioremediation, phytostabilization, phytoextraction, or rhizofiltration (Schnoor, 1997). Applications of phytotransformation include petrochemical sites and storage areas, ammunition wastes, fuel spills, chlorinated solvents, landfill leachate, and agricultural chemicals. 
Plants can directly uptake pollutants from the soil and groundwater through their root systems. Organic and nutrient contaminants are directly taken up and transpired or metabolized within the plant in the application of phytotransformation. Metals are taken up and bound to plant tissue in phytoextraction applications. Specifically for organics, the direct uptake of contaminants will depend upon the octanol-water partition coefficient. Direct uptake is efficient for moderately hydrophobic organic chemicals ( $\left.\log \mathrm{K}_{\mathrm{ow}}=0.5-3\right)$ in shallow contaminated sites. Hydrophobic chemicals with a $\log \mathrm{K}_{\mathrm{ow}}$ greater then 3.0 are bound so strongly to the surface of roots that they cannot easily be translocated within the plant, whereas mobile chemicals that are quite water soluble $\left(\log \mathrm{K}_{\mathrm{ow}}<0.5\right)$ are not as effectively sorbed to roots or actively transported through plant membranes (Schnoor, 1997).

Plants can also remediate pollutants in the soil through rhizosphere bioremediation, phytostabilization, and rhizofiltration. In rhizosphere bioremediation, the plants provide oxygen, bacteria, and organic carbon to encourage the degradation of organics in the soil. The microorganisms in the environment created by the plants, together with the roots of the plants, can degrade more contaminants than could occur in a purely microbial system (Vouillamoz and Milke, 2001). Plants that require large volumes of water can prevent migration of leachate towards groundwater or receiving waters. Roots from vegetation can prevent erosion and provide hydraulic control and are a demonstration of phytostabilization. Finally, rhizofiltration is the use of plants to sorb, concentrate, and precipitate metal and organic contaminants from surface or groundwater.

Plant species are selected for phytoremediation based on the potential to transpire groundwater, the degradative enzymes they produce, growth rates and yield, root-zone depth, and ability to bioaccumulate contaminants. Trees of the Salicaceae family, willow and poplar, are ideal candidates for phytoremediation due to their growth rates and high transpiration rates. Several studies have evaluated the ability for trees from the Salicaceae family to phytoremediate organic and nutrient contaminants such as atrazine, trichloroethylene, and 2,4,6-trinitrotoluene to name a few (Burken and Schnoor, 1997, 1998; Schnoor, 1997; Newman et al., 1995; Newman et al., 1997; Nietch et al., 1999).

\section{SITE HISTORY}

Approximately ten miles north of Baton Rouge, LA and along Baton Rouge Bayou are the Petro Processors Inc. (PPI) sites. The two sites, namely the Scenic Highway and the Brooklawn site, are approximately one mile apart. The 77-acre (combined) sites were operated from a period extending from 1964 to 1979, during which time hazardous waste from a number of industries within the area was disposed of in un-engineered and uncontrolled pits. The site consists of an upland terrace called the "bluff" area and a lower floodplain area called the "batture" area. The bluff area rests mostly on consolidated clayey silt to silty clay marine deposits of the Pleistocene era. The batture area lies within the alluvial plane and is underlain by intermittent clays to sands. Within 
the Brooklawn site, the batture area lies in the floodplain of the Mississippi River. The Baton Rouge Bayou, which originates seven miles north of the site, formerly passed through the site but now passes around the sites and flows into the northern portion of Devil's Swamp.

In total, the estimated original waste disposed of at the site was 320,000 tons. This waste consisted of industrial materials and debris such as bulk rubber and polymers, empty drums, drums filled with semi-solid waste, fragments of plastic, wood, cardboard, coal fines, and metallic slag. Contaminants encountered include hexwastes (hexachlorobutadiene and hexachlorobenzene), halogenated organic solvents (1,2-dichloroethane, tetrachloroethane, etc.), volatile aromatic hydrocarbons (benzene, toluene, etc.), and polynuclear aromatic hydrocarbons (Acar et al., 1995).

NPC Services Inc, which was established by the responsible parties (RP) to clean up the site, after thorough investigation is pursuing hydraulic containment and recovery followed by monitored natural attenuation at the Brooklawn site and monitored natural attenuation at the Scenic Highway site. As part of this monitored natural attenuation, the contribution from phytoremediation is being studied in our research group at Louisiana State University, and this paper presents the results of a phytobuffering study using willows. The specific objectives of this study are to: (i) estimate plant capture of contaminants from contaminated sediment under various flow conditions, (ii) develop a model for phytobuffering rates of the plant "reactor" system, (iii) estimate the buffering effect expected in the bayou-plant systems using the model, and (iv) scale up the rates to representative sections of Baton Rouge Bayou/ Devil's Swamp to estimate buffer capacity of the willows.

\section{EXPERIMENTAL PROCEDURE}

\section{Sediment}

The sediment is a mixture obtained from several locations at the Brooklawn site of Petro Processors Inc. near Baton Rouge Bayou. It is a mixture of clay and sandy sediment, roughly a 50 - 50 mix. Care was used to insure that the same type of sediment as in the bayou is used in the laboratory experiments so that the results from the model would be consistent with the natural system. Finally, sediment in the beds was replaced for each experiment to avoid residual effects from one experiment to another.

\section{Chemicals}

Mixtures of lower chlorinated benzenes, monochlorobenzene (MCB), 1,2 and 1,3-dichlorobenzene (DCB), and 1,2,4-trichlorobenzene (TCB)) were used in this study. All the chemicals were purchased from Aldrich Chemical Company (Milwaukee, WI.) and were used as supplied. These compounds are representative of the degradation products of hexachlorobenzene $(\mathrm{HCB})$ in the Baton Rouge Bayou area at the Petro Processors Inc. Superfund site. Some of the properties of the chemicals are presented in Table 1. 


\section{Plants}

Willows were chosen for this study due to the large numbers present in the Baton Rouge Bayou. The research is focused on two regions within the bayou. Region 1 has willows $45 \mathrm{ft}$ high and $1.67 \mathrm{ft}$ diameter on average, with a tree density of three trees per 10,000 square feet; and region 2 has (on average) smaller willows ( $35 \mathrm{ft}$ high and $1.33 \mathrm{ft}$ diameter) with a higher tree density (30 per 10,000 square feet). The density of dry wood, being used here to represent the plants, is 0.43 grams $/ \mathrm{cm}^{3}$ (Simpson and TenWolde, 1999) USDA Forest Service, 2001).

\section{Preparation and Contamination of the Sediment}

Large debris in sediment was removed using a sieve tray (\#10 Std.), after which the material was air-dried at room temperature. The sediment was run through a grinder to produce a silty mix. Approximately 750 grams were placed in a jar and saturated with distilled water (approximately $200 \mathrm{ml}$ ). The chlorinated benzene solution was prepared just prior to the contamination of the sediment. A pre-determined amount of the test chemical was added to $50 \mathrm{~mL}$ of methanol to prepare a stock solution. A measured amount of the stock is added to each jar to achieve a contamination level of $10-15$ ppm (Jones, 2001). The jars were placed on a tumbler for $40 \mathrm{hrs}$ to uniformly distribute the contaminants. The sediment from all the jars was mixed together and placed into the sheet flow experimental beds. The extraction bed was constructed of stainless steel, as shown in Figure 1. The length of the bed is $50 \mathrm{~cm}$ and the height and width are five $\mathrm{cm}$. The bed was constructed to provide a flat, thin film of water flowing over a flat bed of sediment. For the

Table 1. Physical and chemical properties of the test chemicals (Montgomery, 1997).

\begin{tabular}{||l|c|c|c|c|}
\hline Property & MCB & $\mathbf{1 , 3}$ DCB & $\mathbf{1 , 2}$ DCB & $\mathbf{1 , 2 , 4}$ TCB \\
\hline Chemical Formula & $\mathrm{C}_{6} \mathrm{H}_{5} \mathrm{Cl}$ & $\mathrm{C}_{6} \mathrm{H}_{4} \mathrm{Cl}_{2}$ & $\mathrm{C}_{6} \mathrm{H}_{4} \mathrm{Cl}_{2}$ & $\mathrm{C}_{6} \mathrm{H}_{3} \mathrm{Cl}_{3}$ \\
\hline Molecular Weight $(\mathrm{g})$ & 112.56 & 147.00 & 147.00 & 181.45 \\
\hline Purity & $99.8 \%$ & $98 \%$ & $99 \%$ & $99+\%$ \\
\hline B.P. $\left({ }^{\circ} \mathrm{C}\right)$ & 132 & 173 & 180.5 & 213.5 \\
\hline M.P. $\left({ }^{\circ} \mathrm{C}\right)$ & -45.6 & -24.70 & -17 & 17 \\
\hline Density $\left(20^{\circ} \mathrm{C},\left(\mathrm{g} / \mathrm{cm}^{3}\right)\right.$ & 1.10646 & 1.2881 & 1.3048 & 1.4542 \\
\hline Vapor Press., $\mathrm{mm} \mathrm{Hg}$ & 9 & $1.9-2.3$ & 1.03 & 0.4 \\
\hline Soubility & 1.04 & 0.82 & 9.4 & 0.78 \\
\hline Vapor Density & 4.60 & 6.01 & 6.01 & 7.42 \\
\hline Log Kow & $2.65-2.98$ & $3.38-3.60$ & $3.29-3.75$ & $3.63-4.23$ \\
\hline Log Koc & 2.10 & 2.23 & 2.44 & 2.73 \\
\hline $\begin{array}{l}\text { Henry's Constant } \\
\text { (x10 } 3 \text { atm*m } / \mathrm{mol})\end{array}$ & $3.11-3.93$ & $1.8-3.6$ & $1.2-1.9$ & $0.997-2.32$ \\
\hline
\end{tabular}




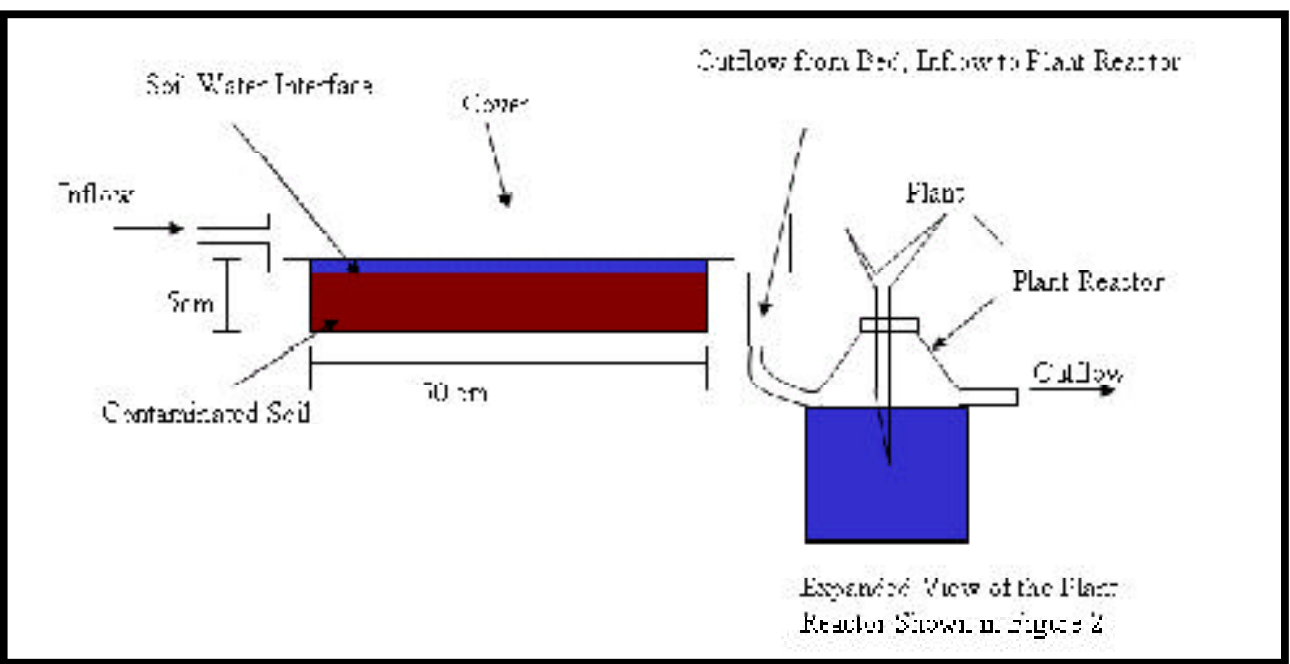

Figure 1. Complete experimental setup (side view).

duplicate runs, (two beds were run in parallel for each experiment) care was taken to insure the same amount of mixture was used. It is important that the level of sediment does not fall above or below the level of the weirs, as the water level must be maintained at $2-3 \mathrm{~mm}$ thickness.

\section{Phytobuffering Experiments}

Distilled water is pumped from a reservoir to the inlet, over the inlet weir onto the sediment, using a multi-cartridge peristaltic pump. Water flows over the sediment in a sheet with a thickness of two to three millimeters. Bed flows varied from $\sim 50-\sim 150 \mathrm{~mL} / \mathrm{hr}$. The retention time was calculated for the laboratory bed. Using the U.S. Geological Survey flow data for the section of the Baton Rouge Bayou with high and low flows for a rain event, the length of the bayou that will provide the same retention time was estimated to be $150 \mathrm{ft}$. The flow in the laboratory thus simulates $150 \mathrm{ft}$ of Baton Rouge Bayou. As the water flows over the contaminated sediment, chlorinated benzenes are transported into the water column and flow to the outlet. The extraction bed is covered with a sealed lid to reduce the loss of volatile organics from the water phase during the experiments.

The contaminated water flows over the second weir and enters the plant reactor. The reactor consists of a $500 \mathrm{ml}$ Pyrex bottle with an inlet attached at a $45^{\circ}$ angle on one side and an outlet attached on the opposite side at a $90^{\circ}$ angle. To prevent backflow, the inlet is attached near the cap of the bottle. The placement of the outlet gives a constant volume of $460 \mathrm{ml}$ in the reactor. To provide continuous mixing, the reactors were placed on magnetic stirrers and are thus modeled as continuous stirred tank reactors, (CSTRs). The effluent from the CSTR was collected and disposed of appropriately.

The willow tree (cuttings obtained from the Brooklawn site at PPI) was placed directly into the CSTR through a 2-cm hole in the cap. Cuttings were developed to a length of 20 inches in a greenhouse for 16 weeks prior to placement in the CSTR. The cap is sealed with a septum, inert 


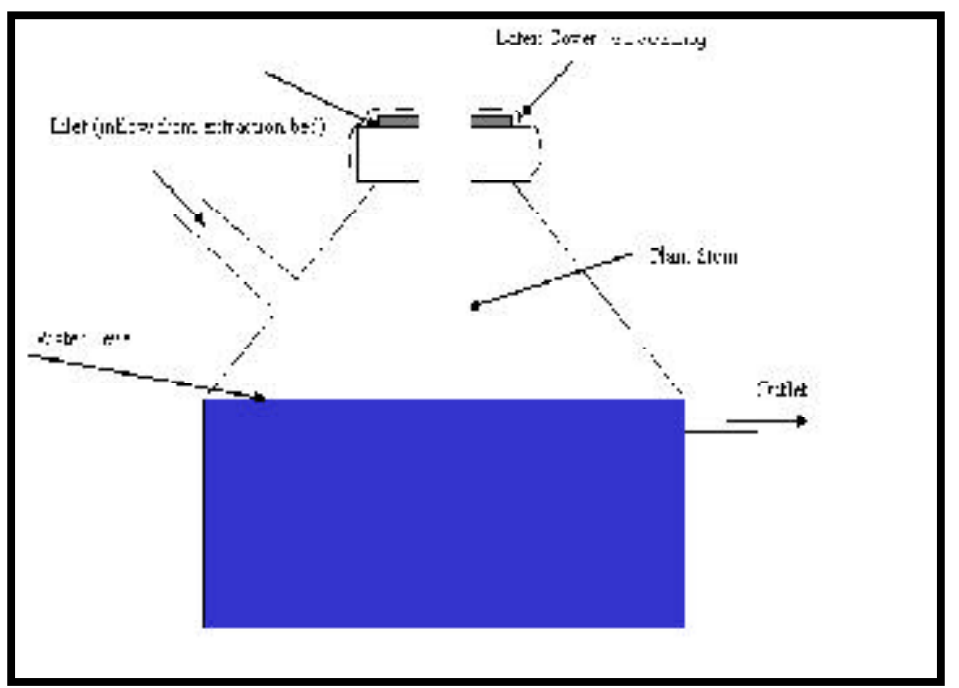

Figure 2. Plant reactor setup with sealed cap.

clay, and latex rubber, as shown in Figure 2. The septum is cut and enclosed around the stem of the tree. Inert clay is used to close the small gap between the tree and the septum. This entire setup was placed in a fume hood. Samples were collected from the outlet of the extraction bed (inlet to the plant reactor) and outlet of the plant reactor. Three different flows, fast $(\sim 150 \mathrm{~mL} / \mathrm{hr})$, slow $(\sim 55 \mathrm{~mL} / \mathrm{hr})$, and cyclical $(\sim 50-150 \mathrm{~mL} / \mathrm{hr})$ were used. The different experimental run codes and test conditions are provided in Table 2. Sampling intervals depend on the flow rates used and ranged from 3 hours to 8 hours (Jones 2001). Samples were collected in EPA certified clear vials of $46 \mathrm{~mL}$ capacity (VWR Scientific, Sugar Land, Texas) and stored in the refrigerator until analyzed (usually within 24 hours).

\section{Analysis of Test Chemicals}

The chlorinated benzenes in the samples were analyzed using a an HP 5890A high resolution gas chromatograph equipped with a an HP 5971 mass spectrometer detector, and fitted with a purge-and-trap unit and auto sampler. A 30-meter capillary column, with a $0.25-0.32 \mathrm{~mm}$ internal diameter and $1.0 \mu \mathrm{m}$ film thickness was used. The injector oven temperature was between 200 and

Table 2. Details of the different experimental runs.

\begin{tabular}{|l|c||c|c|}
\hline \multicolumn{1}{|c|}{ Run Code } & Flow & $\begin{array}{c}\text { Reactor } \\
\text { Medium }\end{array}$ & $\begin{array}{c}\text { Average Flow } \\
(\mathbf{m L / h r})\end{array}$ \\
\hline \hline OCB-8 & Fast & With Plants & 159 \\
\hline OCB-10 & Slow & With Plants & 57 \\
\hline OCB-11 & Cyclic & With Plants & $\begin{array}{c}95(50-150) \\
\text { time cycle 24 hrs }\end{array}$ \\
\hline \hline PCB-1 & Fast & Without Plants & 150 \\
\hline
\end{tabular}


$300^{\circ} \mathrm{C}$. The initial oven temperature was $45^{\circ} \mathrm{C}$. An oven temperature of $180^{\circ} \mathrm{C}$ was used for the analysis, and the time for analysis was 32 minutes.

\section{MODEL DEVELOPMENT}

A model is developed using the mass balance around the plant reactor (Figures 1 and 2). The mass balance for the reactor would consist of a single source that contributes contaminants (loading from the extraction bed) and two sinks that deplete contaminants (outflow from the plant reactor and the reaction within the reactor). The reactor is stirred continuously and is assumed to be well mixed. Losses due to volatilization and photodegradation are minimized and are not considered in the model, thus the losses are limited to the two sinks mentioned above. The basic mass balance around the reactor may be expressed as:

$$
V \cdot \frac{d C_{a}}{d t}=Q \cdot C_{a i}-Q \cdot C_{a}-\left(k_{1} / M p\right) \cdot C_{a} \cdot V-Q_{p} \cdot C_{a}
$$

where

$\mathrm{V}=$ volume of reactor, $\mathrm{mL}$

$\mathrm{Q}=$ flow rate, $\mathrm{mL} / \mathrm{hr}$

$\mathrm{C}_{\mathrm{ai}}=$ the inflow concentration to the plant reactor (outflow concentration from the bed), $\mu \mathrm{g} / \mathrm{L}$

$\mathrm{C}_{\mathrm{a}}=$ outflow concentration from the plant reactor, which is same as that inside the reactor, $\mu \mathrm{g} / \mathrm{L}$

$\mathrm{k}_{1}=$ uptake rate coefficient, gram-plant/hr

$\mathrm{Mp}=$ mass of trees, gram-plant

$\mathrm{Q}_{\mathrm{p}}=$ transpiration rate, $\mathrm{mL} / \mathrm{hr}$

The reaction term is representative of pooled depletion mechanisms by the plant and is represented by the first-order reaction coefficient $\mathrm{k}_{1}$, divided by the mass of the plant $\left(\mathrm{M}_{\mathrm{p}}\right)$, to accommodate scale up of the model results. The last term in equation I allows for the transpiration rate to be included in the model. It is assumed in the model that $\mathrm{Q}_{\mathrm{p}}$ is small, relative to $\mathrm{Q}$. The inlet concentration to the plant reactor is the effluent concentration from the extraction bed, which can be modeled by an exponential decay equation obtained from our earlier research with the sediment beds (Blad, 2001) and other references (Chapra, 1997)

$$
C_{a i}(t)=C_{a i 0} \cdot e^{-k_{2} \cdot t}
$$

where

$\mathrm{C}_{\mathrm{ai}}(\mathrm{t})=$ time-dependent input concentration to the plant reactor from the extraction bed, $\mu \mathrm{g} / \mathrm{L}$

$\mathrm{C}_{\mathrm{a} 0}=$ initial input concentration in the extraction bed (initial bed source concentration), $\mu \mathrm{g} / \mathrm{L}$

$\mathrm{t}=$ time, hrs

$\mathrm{k}_{2}=$ concentration decay rate coefficient, $1 / \mathrm{hr}$. 


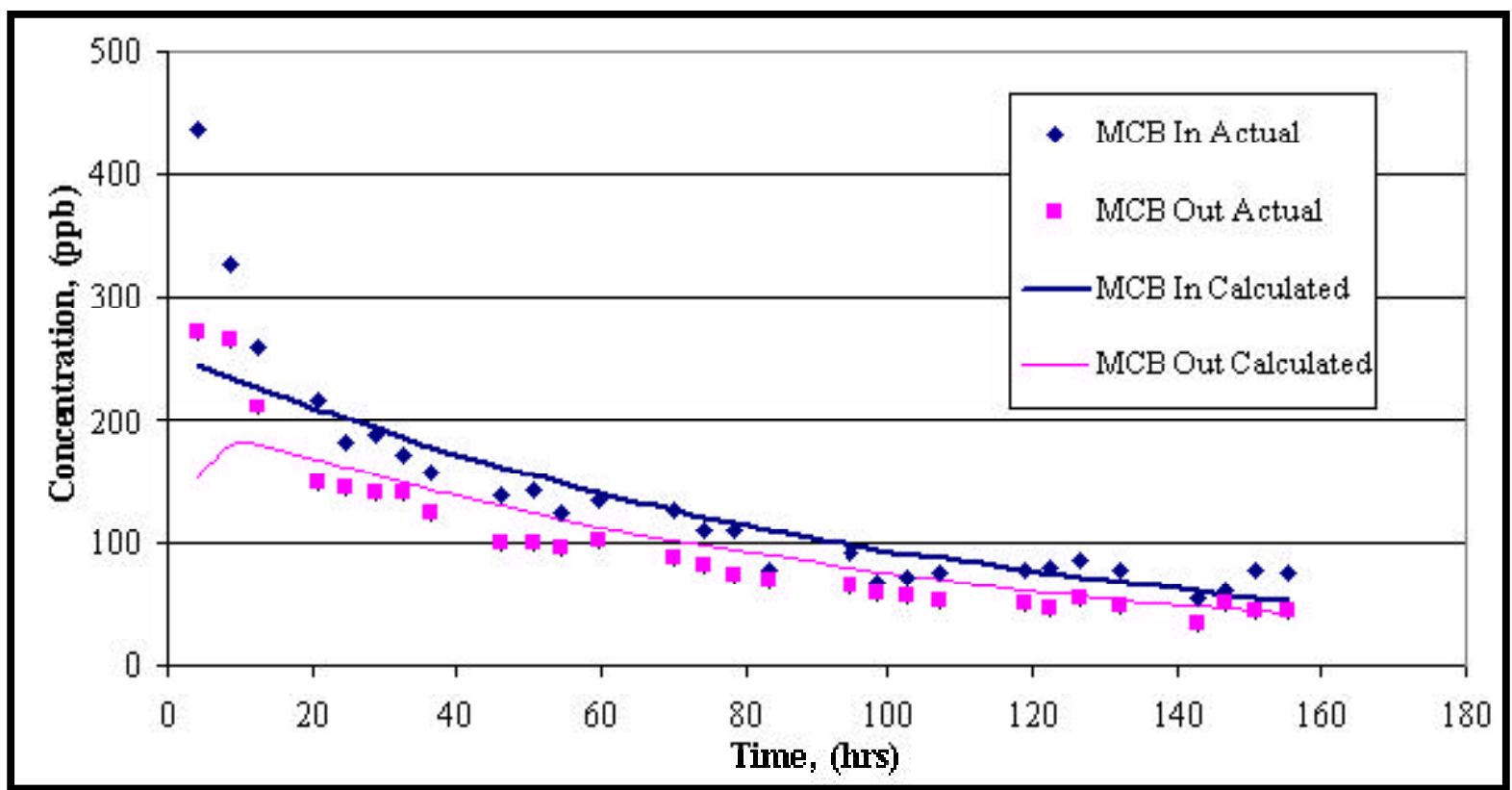

Figure 3. MCB concentration profiles (measured and model predictions) for fast flow experiments with trees.

Rearranging equation I, we obtain the governing non-homogenous first-order ordinary differential equation:

$$
\frac{d C_{a}}{d t}+\frac{1}{\tau \mathrm{K}} C_{a}=\frac{C_{a i}}{\tau}
$$

where

$\tau=$ detention time, $\mathrm{V} / \mathrm{Q}, \mathrm{hr}$

$\mathrm{K}=1 /\left(1+\tau\left[\mathrm{k}_{1} / \mathrm{Mp}+\mathrm{Q}_{\mathrm{p}} / \mathrm{V}\right]\right)$, dimensionless number

By substitution of the inlet concentration expression (equation II) into the mass balance equation (equation IA) and assuming that the plant uptake is a first-order reaction, an expression for the effluent (from the plant reactor) concentration can be obtained as (Jones, 2001):

$$
C_{a}(t)=\frac{C_{a 0}}{-k_{2} \tau+1 / K}\left(e^{-k_{2} t}-e^{-t / \tau K}\right)
$$

All the variables are as defined earlier. This equation allows for scale up if the rate coefficients are determined experimentally. The concentrations of chlorobenzenes entering and leaving the plant reactor are monitored, and the difference represents the loss of contaminant. This loss is used to estimate the value of $\mathrm{k}_{1}$. After linearizing equation III, a commercially available software, MathCAD, is utilized to estimate the dimensionless number, $\mathrm{K}$. From the estimated value of $\mathrm{K}$, an assumed value for $\mathrm{Q}_{\mathrm{p}}$ and equation $\mathrm{I}$, the value of $\mathrm{k}_{1}$ is determined using the following expression:

$$
k_{1}=\left(1-K-\frac{K \tau Q_{p}}{V}\right)\left(\frac{M_{p}}{K \tau}\right)
$$




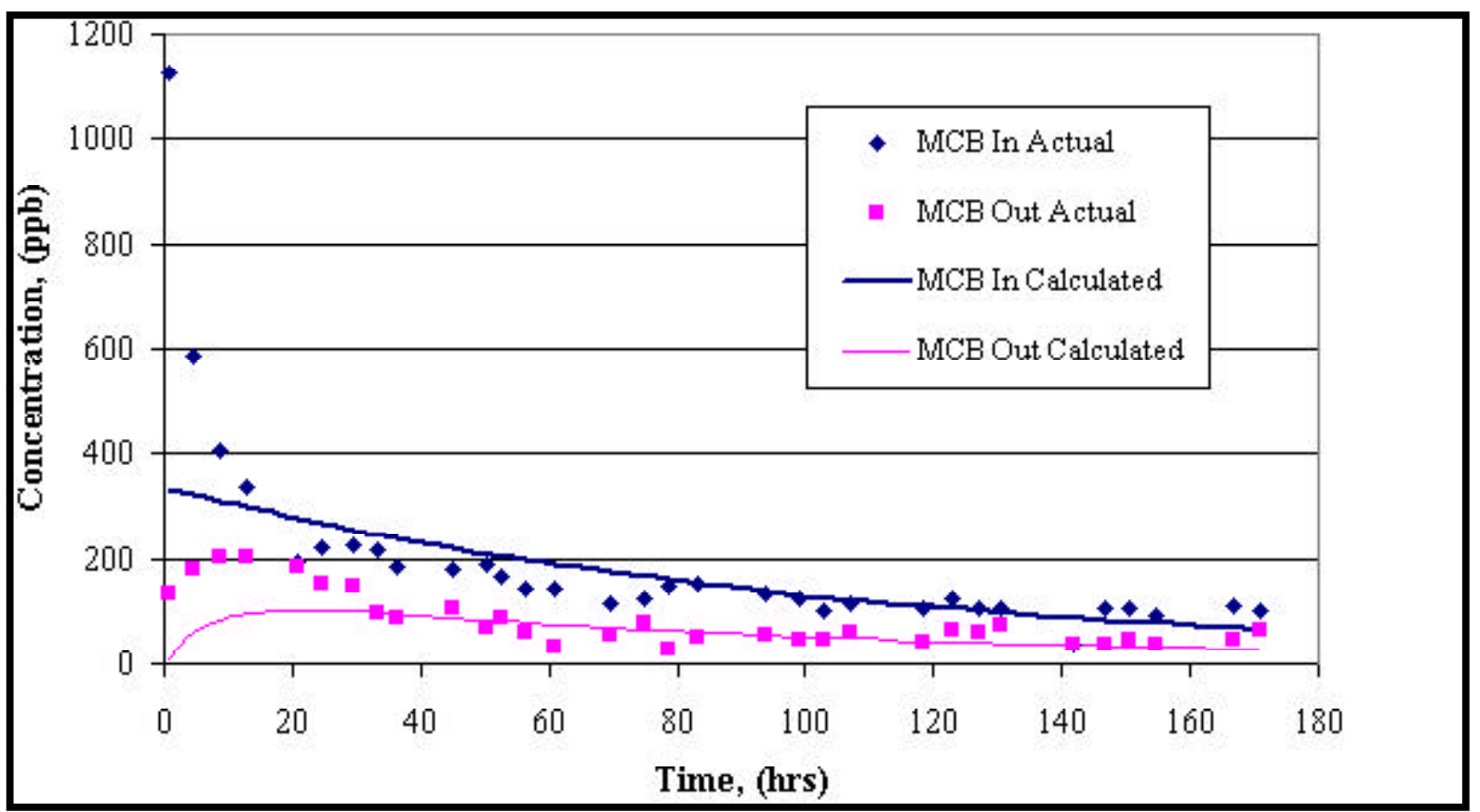

Figure 4. MCB concentration profiles (measured and model predictions) for slow flow experiments with trees.

The transpiration rate $\left(Q_{p}\right)$ is then estimated for different flow rates by approximating the rate coefficient $\left(\mathrm{k}_{1}\right)$ to zero. The expression for $\mathrm{Q}_{\mathrm{p}}$ is given by:

$$
Q_{p}=\frac{(1-K) V}{K \tau}
$$

Using the estimated coefficients and site-specific information such as the mass of trees, flow rate, area, reaction constants obtained from the experiments, and Equations II and III developed above into MathCAD, the concentration profiles (inlet and outlet) with time were obtained. The difference in the inlet and outlet concentrations averaged over the duration of the experiment provided the amount of contaminant taken up by the plants. This value is then used to scale up and determine phytobuffering of the willows at the PPI Superfund site. More details of the model and the solution are explained elsewhere (Jones, 2001).

Table 3. Transpiration rates $\left(\mathrm{Q}_{\mathrm{p}}\right)$ and uptake rate coefficients $\left(\mathrm{k}_{1}\right)$ for phyto-buffering of contaminants.

\begin{tabular}{|l||cc||cc|cc|}
\hline Chemical & \multicolumn{2}{|c|}{ OCB-8 Fast Flow } & \multicolumn{2}{|c|}{ OCB-10 Slow Flow } & \multicolumn{2}{|c|}{ OCB-11 Cyclic Flow } \\
& $\mathrm{Q}_{\mathrm{p}}(\mathrm{mL} / \mathrm{hr})$ & $\mathrm{k}_{1}\left(\mathrm{x} 10^{-3}\right)$ & $\mathrm{Q}_{\mathrm{p}}(\mathrm{mL} / \mathrm{hr})$ & $\mathrm{k}_{1}\left(\mathrm{x} 10^{-3}\right)$ & $\mathrm{Q}_{\mathrm{p}}(\mathrm{mL} / \mathrm{hr})$ & $\mathrm{k}_{1}\left(\times 10^{-3}\right)$ \\
\hline MCB & 1.00 & 5.1 & 4.88 & 34.0 & 0.91 & 39.2 \\
\hline 1,3 DCB & 0.84 & 6.3 & 4.11 & 25.6 & 0.73 & 48.3 \\
\hline 1,2 DCB & 1.00 & 5.1 & 4.90 & 34.1 & 0.90 & 40.7 \\
\hline $1,2,4$ TCB & 0.52 & 8.8 & 3.40 & 18.0 & 0.80 & 45.3 \\
\hline Average & $\mathbf{0 . 8 4}$ & & $\mathbf{4 . 3 2}$ & & $\mathbf{0 . 8 3}$ & \\
\hline
\end{tabular}




\section{RESULTS AND DISCUSSION}

Influent and effluent concentrations of the four chlorobenzenes (MCB, 1,2- and 1,3-DCB and $1,2,4-\mathrm{TCB})$ in the plant reactor are monitored at regular predetermined intervals. These intervals depended on the flow rate and type. All the four compounds showed very similar trends as one would expect, and graphs for only one of the four contaminants, MCB, are presented in Figures 3, 4 and 5, respectively, for fast flow (OCB-8); slow flow (OCB-10); and cyclic flow (OCB-11) with trees (refer to Table 2 for experimental parameters). The discussions made here for MCB would also be true for the other three test contaminants, 1,3-DCB, 1,2-DCB, and 1,2,4-TCB. The observed concentrations of contaminants in the inlet and outlet streams were plotted against time for all the flow conditions (the points in the graphs are actual measurements, and the lines are the estimated values from the model and will be discussed later). Inlet concentration refers to the inlet to the plant-reactor, which would be the same as the outflow concentration from the extraction bed, and the outlet concentration is the effluent from the plant reactor system. The plots show the concentrations of the incoming and outgoing streams to and from the plant-reactor against time. The inlet concentration to the plant reactor would approximately follow exponential decay as discussed in the model development section (equation II). The outlet concentration for the plant reactor increases steadily and reaches a peak before exponentially decaying, which is the typical profile for dilution by mixing. However, due to the sampling intervals used in the study, the initial steady increase in outflow concentration is not so obvious.

For all the three flow regimes, fast, slow, and cyclic, with the willow trees, the plots for MCB (Figures 3-5) show that there is a significant difference in the inflow and outflow concentrations. These differences cannot be explained by the minimal losses expected in these systems as extreme care was taken to minimize or eliminate all potential losses. The difference in the concentrations is

Table 4. Amount of contaminants buffered by the willow trees for the bayou plant systems at both selected areas of Devil's Swamp.

\begin{tabular}{|c|c|c|c|c|c|c|}
\hline \multirow[t]{2}{*}{ Chemical } & \multicolumn{2}{|c|}{ Fast Flow } & \multicolumn{2}{|c|}{ Slow Flow } & \multicolumn{2}{|c|}{ Cyclic Flow } \\
\hline & lb/year ${ }^{1}$ & lbs/yr/acre ${ }^{2}$ & lb/year ${ }^{1}$ & lbs/yr/acre ${ }^{2}$ & lb/year ${ }^{1}$ & lbs/yr/acre ${ }^{2}$ \\
\hline MCB & 21.03 & 40.68 & 6.51 & 12.6 & 9.55 & 18.49 \\
\hline 1,3 DCB & 11.83 & 22.88 & 4.24 & 8.20 & 6.08 & 11.75 \\
\hline $1,2 \mathrm{DCB}$ & 12.84 & 24.84 & 4.18 & 8.10 & 7.21 & 13.94 \\
\hline $1,2,4 \mathrm{TCB}$ & 7.05 & 13.63 & 2.43 & 4.69 & 4.18 & 8.09 \\
\hline Total & 52.8 & 102 & 17.4 & 33.6 & 27.0 & 52.3 \\
\hline
\end{tabular}

${ }^{1}$ The amount estimated is for one region and is same for both the regions.

${ }^{2}$ Obtained by dividing the lb/year column with the acreage of the regions ( 0.517 acres $)$. 


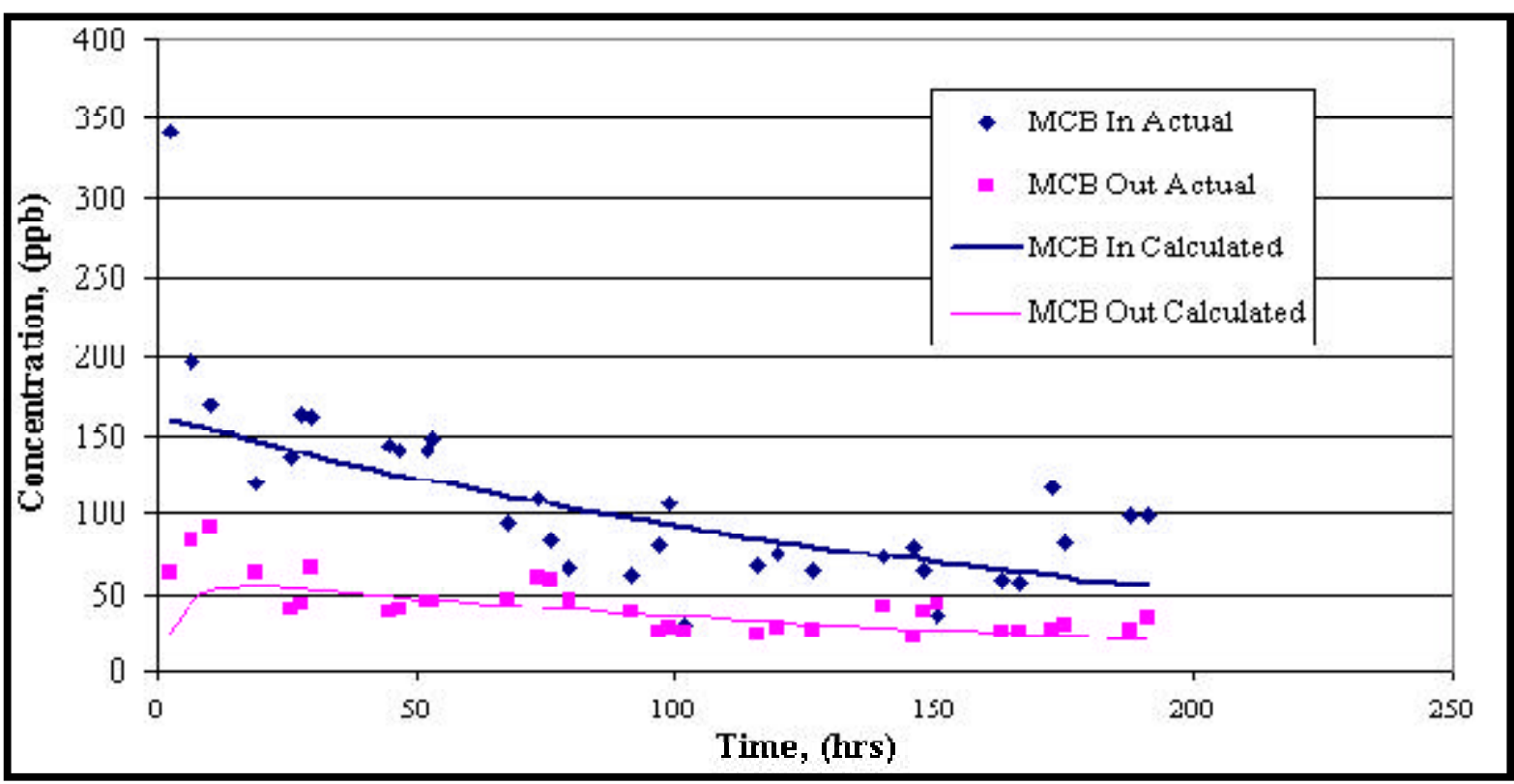

Figure 5. MCB concentration profiles (measured and model predictions) for cyclic flow experiments with trees.

attributed to the buffering provided by the willow trees. No attempt is made here to characterize the buffering provided by the willows with respect to what type of phytoremediation and what fraction. It is possible any one or all of the phytoremediation mechanisms could be applicable here; however, all these are lumped in the current study under phytobuffering. The difference in concentrations of the inflow and outflow, when averaged over the duration of the experiment, would give the estimate for phytobuffering provided by the willow trees. As can be seen from these figures, the willow trees seem to provide significant buffering of the contaminants.

Two additional components of the buffering effect should also be noted here. First, the cyclic study (Figure 5) shows that a higher degree of buffering occurs in dynamic systems as the effluent curve slopes for all compounds are significantly reduced when compared to that for fast and slow flow systems. Second, the cyclic flow results show a dampening effect when compared to previous Table 5. Scaled phyto-buffering estimated for the entire contaminated area of Devil's Swamp (100 acres) over the past 20 years.

\begin{tabular}{|l||c|c||c|}
\hline Flow & $\begin{array}{c}\text { Phyto-buffering on } \\
\text { 100 Acres, (lb/yr) }\end{array}$ & $\begin{array}{c}\text { Phtyo-buffering on } \\
\text { 100 Acres for 20-Year } \\
\text { Period, (lb) }\end{array}$ & $\begin{array}{c}\text { Tons (2000 lb) of } \\
\text { Contaminants buffered } \\
\text { over 20-Year Period }\end{array}$ \\
\hline \hline Fast Flow & 10203 & 204060 & 102 \\
\hline \hline Slow Flow & 3359 & 67180 & 33.6 \\
\hline Cyclic Flow & 5227 & 104540 & 52.3 \\
\hline
\end{tabular}


work on cyclic flux from bed sediment performed in this laboratory (Blad, 2001). The peaks expected in concentration are reduced significantly in the effluent when compared to the reactor influent, again attesting to the plant buffering effect. Thus, both overall concentration and peak concentrations are reduced by the influence of the plant buffering.

Results for the reactor system without any plants, performed using only one of the contaminants, $\mathrm{MCB}$, and fast flow rate (PCB-1), are presented in Figure 6. As can be seen from the plot, for the reactor without the plants, the differences in the concentration of the two streams (influent and effluent) to and from the plant reactor is very insignificant compared to systems that had plants. For experiments which had plants (Figures 3-5), there is a significant difference between influent and effluent concentration in the plant reactor. The significant differences are attributed to buffering provided by the trees during the experiment. The small differences seen in the inlet and outlet concentrations for the system without plants and a fraction of the losses in the systems with plants could indicate some possible losses, such as losses to the vapor phase and losses during sampling of the influent and effluent, though attempts were made to minimize them. Clearly, the willow trees do provide a degree of buffering in the flowing systems, which are modeled to represent the Baton Rouge Bayou area of the PPI Superfund site. When comparing Figure 6 (without trees) to results in Figure 3 (with trees), the curves appear different due to the scales used in the figures being different. Also, Figure 3 includes model prediction lines, and Figure 6 shows only trend lines without model fit to the data.

Concentration profiles for 1,3-DCB, 1,2-DCB, and 1,2,4-TCB for all flow conditions exhibited similar characteristics of buffering and thus are not included in the manuscript. The discussions are, however, valid for all the four test compounds..

The rate coefficients, $\mathrm{k}_{1}$, for the uptake of contaminants by the plants, were determined as explained in the model development section. The slope of the line obtained from the plot of the linearized form of Equation III is used to determine the non-dimensional pooled variable, K. From

Table 6. Uptake of contaminants estimated using general uptake equation (Burken and Schnoor, 1998; Schnoor, 1997).

\begin{tabular}{|l|c|c|c|}
\hline Chemical & Area One (lbs/yr) & Area Two (lbs/yr) & Total (lbs/yr) \\
\hline MCB & 0.44 & 4.25 & 4.70 \\
\hline 1,3 DCB & 0.30 & 2.55 & 2.85 \\
\hline \hline 1,2 DCB & 0.30 & 2.70 & 3.00 \\
\hline $1,2,4$ TCB & 0.24 & 2.40 & 2.61 \\
\hline Total & & & $\mathbf{1 2 . 2}$ \\
\hline
\end{tabular}




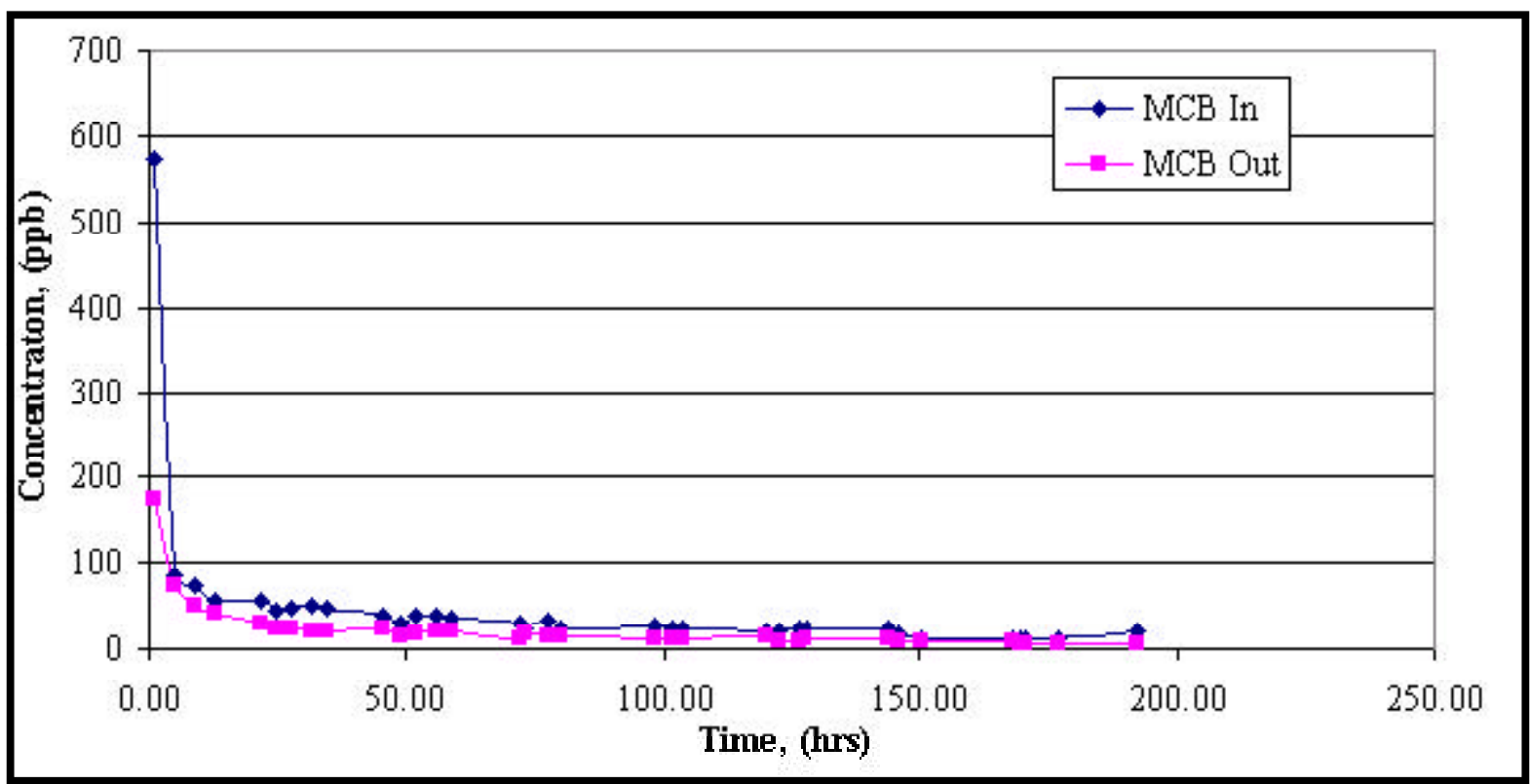

Figure 6. MCB concentration profiles (measured) for fast flow experiments without trees.

the value of $K$, and an assumed value of transpiration rate $\left(Q_{p}\right)$, the rate coefficient $\left(\mathrm{k}_{1}\right)$ was determined using Equation IV. The estimated rate coefficients $\left(\mathrm{k}_{1}\right)$ are presented in Table 3 for MCB and the other three chlorobenzenes, 1,3-DCB, 1,2-DCB, and 1,2,4-TCB. These coefficients are used in the next section to estimate buffering capacities of the willows, as found in the contaminated area of the Devil's Swamp in the Baton Rouge Bayou. As one examines the $\mathrm{k}_{1}$ values, it is noted that the slow flow conditions result in a rate coefficient that is about three to six times that of the fast flow condition. There does not seem to be any direct correlation between the rate coefficient and the octanol-water partition coefficient for the four chlorobenzenes used in the study. The higher buffering or uptake rates for the slow flow are attributed to the increased residence time in the plantreactor for slow flow conditions. However, it should also be noted that cyclic flow uptake rate is marginally higher than that found for the slow flow condition. This observation was also expected due to perturbation of the system from equilibrium and increased uptake, as was found in the flux cycle experiments on bed sediment performed earlier (Blad, 2001). Thus, while slow flow conditions increase buffering due to increased residence time, cyclic studies indicate that dynamic system buffering is more representative of high flow than for low flow conditions.

With the rate coefficients, $\mathrm{k}_{1}$, for the plant uptake known (in the order of $10^{-3}$ ), we approximated these coefficients to zero to simplify the transpiration rate estimation (equation $\mathrm{V}$ ). The transpiration rates $\left(\mathrm{Q}_{\mathrm{p}}\right)$ are presented in Table 3. From examining the transpiration values, one will note that slow flow has a transpiration rate about five times that of fast or cyclic flow. This result may be due to increased residence times of the plant reactor for slow flow conditions, allowing the plants to uptake more material in a more stable system when compared to the dynamic and fast flowing reactor. Cyclic and fast flow experimental transpiration rates were found to be approximately 
equal and only $20 \%$ of the value found at slow flow conditions. Also, the model used assumed that the transpiration rates were small, relative to the flow through the reactor. This assumption may affect the results because at slow flow, the transpiration flow is approximately $10 \%$ of the flow through the reactor.

Inflow and outflow concentrations are estimated using the experiment-specific data such as flow rate, mass of trees, transpiration rates, and the rate coefficient in the model (equation III) developed in this study. The lines shown in Figures 3- 5 are the estimated concentrations from the model. The calculated model results show a reasonably good fit to the data for all the experiments except for the initial drop in contaminant concentration (at the start of the experiment). The model results obtained using the site-specific data instead of the experiment-specific are then used to estimate the buffering capacity of the willow trees at the PPI site.

\section{ESTIMATION OF BUFFER POTENTIAL AT THE PPI SITE}

The utility of the results from this study is in the estimation of the buffer potential of the willows at the actual site (such as the two regions of the Devil's Swamp wherein the Baton Rouge Bayou flows) by scale up of the experimental results. As explained in the experimental section, region 1 has willows $45 \mathrm{ft}$ high and $1.67 \mathrm{ft}$ diameter with a tree density of three trees per 10,000 square feet, and region 2 has smaller willows ( $35 \mathrm{ft}$ high and 1.33 diameter) with a higher tree density ( 30 per 10,000 square feet). Though the density of the trees is different in the two regions of the swamp, the total mass of trees at both regions is roughly the same, and thus we would expect similar buffering at both the regions. The density of the willow trees is assumed to be $0.43 \mathrm{~g} / \mathrm{cm}^{3}$, as dry wood (Simpson and TenWolde, 1999; USDA, 2001). Input and output concentrations profiles for the bayou plant systems at the site are obtained in a similar way as the experimental plant reactor system but by using site-specific parameters such as flow, mass of trees on the site, a scale up transpiration rate based upon the mass of trees, and the willow cuttings' transpiration rate. The difference in the input and output concentrations averaged over a specified period of time would then be used to estimate the buffering provided by the willows for the four test contaminants at the site. The units are converted from $\mu \mathrm{g} / \mathrm{hr}$ to lb/year. The estimated buffering for each of the contaminants for the three flow conditions used in the study are presented in Table 4 (values in the first column for each flow). The estimated values (lbs/year) for each area were then divided by the total area of each region surveyed for willows, which totals approximately 0.517 acres. Results are reported in Table 4 as amount of contaminant buffered by the trees in lb/year/acre (the second column under each flow condition). The total of the four chlorobenzenes buffered at each area is also reported in the table for the three flow conditions. Total buffering provided by the willows for the entire contaminated area of the Devil's Swamp, which is about 100 acres (the original site was 77 acres), and for the age of contamination at the site, which is approximated to 20 years (this is 
approximately the time for the material that went into the swamp after the lagoon dike failed), is estimated and presented in Table 5. The buffering capability of the trees, as can be seen from the table, range from about 34 tons for slow flow, to 52 tons for cyclic flow, to 102 tons for fast flow, with an average of about 63 tons over the 20-year period, which is roughly the age of contamination in the bayou/swamp area. As stated in the introduction, about 320,000 tons of contaminants were buried at the site, and the contribution from phytobuffering for the four test contaminants, though small compared to the total, is still very high. The obvious assumption here is that the willows at the site have had the same density and mass over the 20-year period, and the contaminant conditions remained the same at the site over the same time period. However, the estimate of 63 tons of contaminant buffering through the willow trees around the Baton Rouge Bayou is very significant and may explain why little or no contaminants are found in the water column, unless some form of sediment disturbance has released the contaminants.

Results of our study are compared to those of Schnoor (1997) and Burken and Schnoor (1998). Schnoor (1997), in his technology evaluation report, presented the following general uptake equation for the mainly organic contaminants:

$$
\text { Uptake }=(T S C F)(T)(C)
$$

where:

$\mathrm{TSCF}=$ transpiration stream concentration factor, dimensionless, which is estimated from the octanol-water partition coefficient using the relationship (Burken and Schnoor, 1998) $\mathrm{TSCF}=0.75 \exp \left\{-\left[\left(\log \mathrm{K}_{\mathrm{ow}}-2.50\right)^{2} / 2.4\right]\right\}$ $\mathrm{T}=$ transpiration rate of tree, $\mathrm{L} /$ year-tree $\mathrm{C}=$ aqueous-phase concentration of contaminant in groundwater, $\mathrm{mg} / \mathrm{L}$

Transpiration stream concentration factor was estimated for the four test contaminants using the above relationship. An average octanol-water partition coefficient from the values reported (Montgomery, 1997) was used to estimate this factor. The transpiration rates of 660-1000 gallons of water per tree per year (average 800 gallons per tree per year) were reported by Schnoor (1997) for the mature phreatophyte trees (poplar, willow, and other trees) and used here. The aqueous concentration of about $15 \mu \mathrm{g} / \mathrm{L}$ (based on our soil-phase concentration) was used. The plant uptake was calculated for both the selected regions of the Devil's Swamp and reported in Table 6. Here the two regions would show different uptake as the number of trees was much higher in region 2, and thus had a much higher uptake than would be expected in region 1 . Total uptake for all contaminants is $12.2 \mathrm{lb}$ /year for the two areas combined. The comparable number from our study would be $105.5 \mathrm{lb} / y e a r$ for fast flow, $34.7 \mathrm{lb} / \mathrm{yr}$ for slow flow, and $54 \mathrm{lb} / \mathrm{yr}$ for cyclic flow, with an average of $65 \mathrm{lb} / \mathrm{yr}$. When it is extrapolated to the entire contaminated area of the swamp for the age of contamination, the total uptake by the willows would be about 12 tons. It should also be noted that our model estimates provided here are pooled phytoremediation estimates rather than 
just the uptake by the plants, as is the case for general uptake equation. Also, while the equation given by Schnoor does not take into account site specifics, flow dynamics, or experimental design, it provides a reasonable estimate. The general uptake equation results are within an order of magnitude (about five times), compared with the results from our mathematical model. We believe that the mathematical model developed here, which is based on experimental data, is a better tool to accurately determine the buffering provided by the willow trees for the system studied. The mathematical model shows higher buffering or uptake rates, compared to the general uptake equation, and thus is showing higher attenuation of the contaminants on the site.

\section{ACKNOWLEDGEMENTS}

This work was supported through LSU's role as expert to the U.S. District Court, Middle District of Louisiana, and in cooperation with NPC Services, Inc., managers of the cleanup of the Petro Processors, Inc. site.

\section{REFERENCES}

Acar, Y.B., W. D. Constant, and M. R. Taha, 1995. "The PPI Superfund Site: Remedial Measures and Alternatives," Proceedings of Specialty Conference (Geotechnical and Environmental Division, ASCE), New Orleans, LA, February 24-26, 1995.

Blad, M., 2001. Mass Transfer of 2,4-6 Trinitrotoluene and Lower Chlorinated Benzenes from Sediment into Water, Ph.D. Dissertation, Department of Civil and Environmental Engineering, Louisiana State University, Baton Rouge, LA.

Burken, J.G. and J.L. Schnoor, 1997. "Uptake and Metabolism of Atrazine by Poplar Trees," Environ. Sci. Technol., Vol. 31, No. 5, pp 1399 - 1406.

Burken, J.G. and J.L. Schnoor, 1998. "Predictive Relationships for Uptake of Organic Contaminants by Hybrid Poplar Trees," Environ. Sci .Technol., Vol. 32, No. 21, pp 3379 - 3385.

Chapra, S.C., 1997. Surface Water-Quality Modeling. The McGraw-Hill Companies, Inc. New York. pp $47-51,71-73$.

Jones P.B., 2001. "Phytobuffering of Lower Chlorinated Benzene Contamination Via Willows at the PPI Superfund Site,” M. S. Thesis, Department of Civil and Environmental Engineering, Louisiana State University, Baton Rouge, LA.

Montgomery, J.M.,1997. Groundwater Chemicals Desk References, CRC Press, Boca Raton, FL.

Newman, L.A., M. Gordon, N. Choe, J. Duffy, G. Ekuan, P. Heilman, I. Muiznieks, M. Ruszai, B. Shurtleff, S. Strand, and J. Wilmoth, 1995. "Phytoremediation of Trichloroethylene with Hybrid Poplars," Environ. Health Perspectives, Vol. 29, No.7, pp. 318 - 323.

Newman, L.A., S. Strand, N. Choe, J. Duffy, G. Ekuan, M. Ruszai, B. Shurtleff, J. Wilmoth, P. Heilman, and M. Gordon, 1997. "Uptake and Biotransformation of Trichoroethylene by Hybrid Poplars,” Environ. Sci. Technol., Vol. 31, No. 4, pp. 1062 - 1067. 
Nietch, C.T., J.T. Morris, and D.A. Vroblesky, 1999. "Biophysical Mechanisms of Trichloroethene Uptake and Loss in Baldcypress Growing in Shallow Contaminated Groundwater," Environ. Sci. Technol., Vol 33, No. 17, pp 2899 - 2904.

Nyer E.K. and E.G. Gatliff, 1996. "Phytoremediation," Groundwater Monitoring and Review, pp. 58 - 61, Winter 1996.

Rock, S.A. and P.G. Sayre, 1998. "Phytoremediation of Hazardous Wastes: Potential Regulatory Acceptability," Remediation. Autumn, pp 5-17.

Schnoor, J.L., 1997. Phytoremediation, Groundwater Remediation Technologies Analysis Center, Pittsburgh, PA.

Simpson, W. and A. TenWolde, 1999. Wood Handbook_Wood as an Engineering Material. Gen. Tech. Rep. FPL-GTR-113. Madison, WI., U.S. Department of Agriculture, Forest Service, Forest Products Laboratory. Chapter 3.

U.S.D.A. Forest Service, 2001. Center for Wood Anatomy Research, Madison, WI. 53705-2398. www.USDA.gov

Vouillamoz, J. and M.W Milke, 2001. "Effect of Compost in Phytoremediation of Diseal-Contaminated Soils," Water Science and Technology. Vol. 43, No. 2, pp 291 - 295.

Original Manuscript Received: April 3, 2001

Revised Manuscript Received: December 21, 2001 